\title{
Impedance-voltage functions in the white rat with chronic body electrode implants'
}

\author{
Miehael P. Silver, William N. Sehoenfeld, Arthur G. Snapper and Bernard Locke \\ VA HOSPITAL, NEW YORK CITY
}

\begin{abstract}
Abstraet
Electrical properties of shock "punishment" delivered from implanted electrodes were studied. Subjects were six male albino rats, with four of the subjects under nembutal anesthesia and two not anesthetized. In addition, measures were taken at various times after electrode implantation so as to observe the effect, if any, of age of implant. Impedance characteristics at high and low voltages show that the rat is not a simple resistor. Anesthesia is not an important variable but age of implant seems important at low voltages.
\end{abstract}

\section{Problem}

Impedance measurements are reported for six male Sprague-Dawley white rats (6-9 months old) as a function of impressed voltage, using chronic body electrode implants. Although previous studies with rats have utilized implanted electrodes (e. g., Feirstein \& Miller, 1963; Hendry \& Hendry, 1963), they have not explored systematically the impedance characteristics of the organism. This has been done in the pigeon by Sidley and Schoenfeld (1963).

\section{Method}

Electrodes of \#30 gauge teflon coated silver wire were implanted subcutaneously in the right shoulders of the rats. The electrodes were about $3 / 8$ in apart, and were formed by twisting together two strands of insulated wire and cutting the tips so that the exposed electrode areas consisted only of the cross-sections of the two wires. Separation of the tips was maintained by fixing them with a drop of dental acrylic cement. The electrode wires were led subcutaneously to a connector socket mounted on the skull. The socket was connected by external cable to the shock source. A shielded transformer supplied 60 cycle AC across a precision $10 \mathrm{~K}$ ohm resistor in series with both the animal and a $1 \mathrm{~K} \mathrm{ohm}$ precision resistor. Applied voltage was calibrated on an oscilloscope, and voltage drop across the $1 \mathrm{~K}$ ohm resistor was read from the oscilloscope. Impedances were calculated by Ohm's law.

Eight voltages (all given in root mean square) were used: $1.38,2.76,5.53,11.04,22.09,44.19,88.38,176.75$. At each voltage the rats were given a train of ten 60-millesec. pulses at a rate of 1 pulse per sec. Measurements were made first in an ascending, then a descending, series of voltage magnitudes. Approximately 90 sec. of "rest" separated both series and voltage values.

Initial measurements were made on 4 animals under nembutal anesthesia (Rats 20,21, 22, and 23) and on 2 non-anesthetized animals (Rats 24 and 25). The drug dosages, which included chloral hydrate supplements, were those recommended by Valenstein (1961). These first measurements were made on the several animals at varying times after implantation: Rat 20, 32 days; Rat 21, 5 days; Rat 22, 18 days; Rat 23, 20 days; Rat 24, 4 days; Rat 25, 4 days. Redeterminations were then made after the initial measurements as follows: Rat 20 , 11 days (thus making a total of 43 days after implantation); Rat 21, 26 days (31 days after implantation); Rat 22,20 days (38 days after implantation); Rat 23, 18 days (38 days after implantation); Rat 24, 9 days (13 days after implantation); Rat 25, 7 days (11 days after implantation).

\section{Results}

In general, impedance remained constant over the higher voltages. The functions in Fig. 1 show that, for most animals and for both ascending and descending series, impedance remains between $5-15 \mathrm{~K}$ ohms at $5.53 \mathrm{v}$ and above. Below $5.53 \mathrm{v}$, impedance is higher, although this is more characteristic of the ascending series, and there is some variability among animals on this score. There are no major differences between anesthetized and non-anesthetized animals. The latter

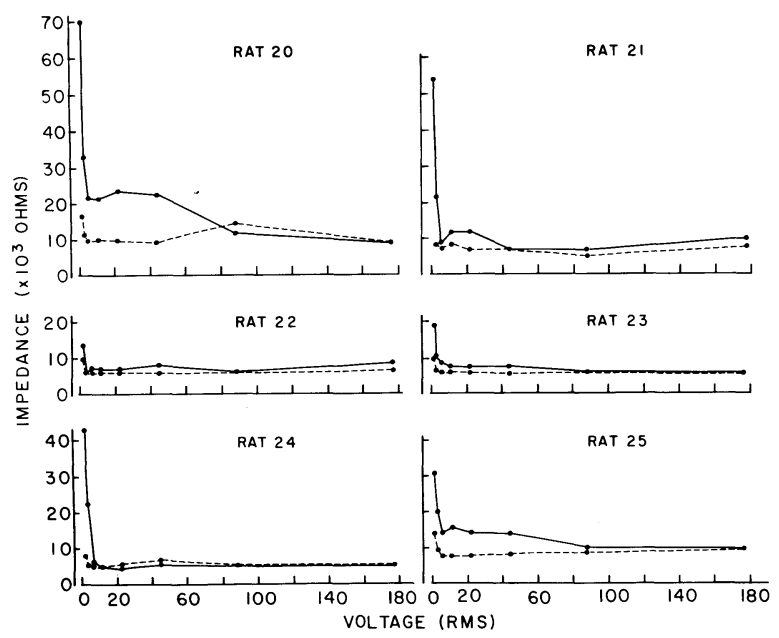

Fig. 1. Impedance measurements from chronically implanted body electrodes in white rats as a function of impressed voltage. Data points connected by solid lines indicate ascending series of voltage magnitude; those connected by dotted lines, descending series. Measurements for Rats $20,21,22$, and 23 were taken under nembutal anesthesia; those for Rats 24 and 25 while non-anesthetized. 
group showed moderate distress reactions to shock, and at only the highest two voltages.

Redeterminations (not shown) indicate that as age of implant increases, the impedances of all animals rise, although there is considerable variability in the rate and magnitude of these measurements. Ingeneral, however, the rise is greatest at low voltages and least at the high ones, and descending series measurements continue to maintain a position somewhat below the ascending ones.

Impedance for Rat 21 at the lowest voltage, $1.38 \mathrm{v}$, is omitted from the descending series function of Fig. 1 because the experimenter did not regard his reading as trustworthy (an oscilloscope camera was not available), a difficulty which arose from distortion of the $\mathrm{AC}$ wave form, sometimes severe, at both ends of the voltage continuum.

These results, transformed into current flow, are comparable to those obtained with the pigeon (Sidley \& Schoenfeld, 1963). In the present study, the fact that the relationship between voltage and impedance cannot be expressed by a linear equation, such as Sidley and Schoenfeld reported, indicates (as did also the wave form distortions at high and low voltages) that the rat is not a simple resistor. The latter authors did note, however, a non-linear relationship below 4 volts (peakto-peak) in the pigeon. The main differences between the two sets of data seem to be the greater impedance of the rat and the increase in impedance with age of implant. The present impedance measurements are of the same magnitude, however, as those given by Hendry and Hendry (1963) for their white rats. The precise source(s) of the difference between the present data and those of Sidley and Schoenfeld remain to be specified.

\section{Referenees}

FEIRSTEIN, A. R., \& MILLER, N. E. Learning to resist pain and fear: effects of electric shock before versus after reaching goal. J.comp. physiol. Psychol., 1963, 56, 797-800.

HENDRY, D. P., \& HENDRY, L. S. Partial negative reinforcement: fixed ratio escape. J. exp. Anal. Beh., 1963, 6, 519-523.

SIDLEY, N. A., \& SCHOENFELD, W. N. Induced electric current flow in the pigeon as a function of impressed voltage and pulse frequency. J.exp. Anal.Beh., 1963, 6, 99-100.

VALENSTEIN, E. S. A note on anesthetizing rats and guinea pigs. J. exp. Anal. Beh., 1961, 4, 6.

Note

1. This study was supported in part by Research Grant MH-08480-01 from NIMH to W. N. Schoenfeld. Reprints may be obtained from W. N. Schoenfeld, Department of Psychology, Schermerhorn Hall, Columbia University, New York, N. Y. 10027. 